\title{
Numerical Analysis of Fluid Flow on Wall Cylinder Circular with $K$ - $\varepsilon$ Modeling for a High Reynolds Rate
}

\section{Analisa Numerik Aliran Fluida pada Dinding Silinder Sirkular dengan Pemodelan K- $\varepsilon$ untuk Bilangan Reynolds yang Tinggi}

\author{
M. Yasep Setiawan ${ }^{1 *}$, Wawan Purwanto ${ }^{1}$, Wanda Afnison ${ }^{1}$, Nuzul Hidayat $^{1}$
}

\begin{abstract}
This study discusses the numerical study of two-dimensional analysis of flow through circular cylinders. The original physical information entered in the equation governing most of the modeling is transferred into a numerical solution. Fluid flow on two-dimensional circular cylinder wall using high Reynolds $k-\varepsilon$ modeling (Re =106), Here we will do 3 modeling first oder upwind, second order upwind and third order MUSCL by using $k-\varepsilon$ standard. The general procedure for this research is formulated in detail for allocations in the dynamic analysis of fluid computing. The results of this study suggest that MUSCL's third order modeling gives more accurate results better than other models.
\end{abstract}

\section{Keywords}

Numerical method, cylinder, turbulent flow, $k$-E modeling.

\begin{abstract}
Abstrak
Penelitian ini berfokus pada studi numerik yang berfokus pada analisis dua dimensi aliran melalui silinder sirkular. informasi fisik asli yang masuk dalam persamaan yang mengatur sebagian besar pemodelan ditransfer ke dalam solusi numerik. Aliran fluida pada dinding silinder sirkular dua dimensi menggunakan pemodelan $\mathrm{k}-\varepsilon$ bilangan Reynolds yang tinggi $\left(\mathrm{Re}=10^{6}\right)$, Disini akan dilakukan 3 pemodelan yaitu first oder upwind, second order upwind, dan third order MUSCL dengan menggunakan $\mathrm{k}-\varepsilon$ standart. Prosedur umum untuk penelitian ini dirumuskan secara rinci untuk alokasi dalam analisis dinamis komputasi fluida. Dari penelitian ini disimpulkan bahwa pemodelan third order MUSCL memberikan hasil yang lebih akurat lebih baik dari model lain.
\end{abstract}

\section{Kata Kunci}

Numerical method, cylinder, turbulent flow, k- $\varepsilon$ modeling

${ }^{1}$ Jurusan Teknik Otomotif, Universitas Negeri Padang

Jln. Prof. Dr. Hamka Air Tawar Padang 25131 Indonesia

*m.yasepsetiawan@ft.unp.ac.id

Submitted : July 29, 2019. Accepted : August 26, 2019. Published : September 01, 2019. 


\section{PENDAHULUAN}

Aliran fluida di sekitar dinding silinder salah satu masalah yang klasik dalam mekanika fluida. hal ini sangat menarik untuk diteliti dalam aplikasi dunia teknik, misalnya masalah aliran fluida pada jaringan pipa laut, lubang penambah (risers), tiang pendukung platform lepas pantai dan lain-lainnya, banyak aplikasi-aplikasi teknik dalam menganalisa suatu aliran untuk bilangan Reynold $\left(R e=U_{\infty} D / v\right)$ Dimana $\left(U_{\infty}\right)$ merupakan kecepatan aliran, (D) adalah diameter dan $v$ adalah viskositas kinematik dengan nilai khusus Re antara $\left(10^{6}\right)-\left(10^{7}\right)$. Hal ini juga berlaku untuk aliran superkritis $\left(3,5 \times 10^{5}<\operatorname{Re}<1,5 \times 10^{6}\right)$ dan aliran transkritikal $(\operatorname{Re}>$ $\left.3,5 \times 10^{5}\right)$.

Masalah ini juga telah disampaikan oleh Sumeria dan Fredsøe [1]. Apabila kita melakukan penelitian suatu aliran dengan bilangan Reynold tinggi pasti membutuhkan ketelitian yang tinggi pada saat pengukuran aliran fluida selain itu faktor human error juga berpengaruh dan penelitian ini membutuhkan biaya yang sangat mahal. Oleh karena itu alternatif yang terbaik adalah dengan menggunakanComputational Fluid Dynamics (CFD).

Schulz dan Meling [2], mereka menggunakan metode multi-strip menganalisis interaksi aliran pada riser fleksibel yang panjang. Menggunakan analisa numerik dua dimensi (2D) dengan persamaan Unsteady Reynolds Averaged Navier Stokes (URANS) (pemodelan turbulensi Spalart-Allmaras) hampir sama dengan metode elemen hingga (a finite element structural dynamic response model) disini analisanya juga dikombinasi dengan 3D untuk memprediksi akibat tekanan dari pusaran yang bergetar vortex induced vibration (VIV) dan perubahan riser itu sendiri.

Chaplin dkk. [3] juga membandingkan hasil penelitian di laboratorium dengan analisa numerik akibat vortex induced vibration (VIV) menghasilakan 11 model numerik yang berbeda, hal ini menunjukan hasil perbandingan metode empiris lebih baik daripada menggunakan metode numerik dengan Computational Fluid Dynamics (CFD). Mungkin disebabkan karena ketidakpastian turbulensi pada pemodelan Computational Fluid Dynamics (CFD).

Saat ini belum banyak analisa aliran fluida dengan bilangan Reynolds yang sangat tinggi $\left(\operatorname{Re}>10^{6}\right)$ menggunakan metode numerik di sekitar dinding silinder sirkular untuk aliran fluida yang komplek. Tapi untuk Direct Numerical Simulation (DNS) untuk menganalisa aliran dengan bilangan Reynolds yang tinggi hasilnya tidak maksimal dan hampir tidak tercapai, ada beberapa hasil numerik yang dihasilkan untuk refrensi $\left(\operatorname{Re}>10^{6}\right)$ dari Catalano dkk. Singh dan Mittal [4], mereka menganalisa dan membandingkan aliran fluida pada dinding silinder licin dengan pemodelan tiga dimensi (3D) menggunakan Large Eddy Simulation (LES) dan Unsteady Reynolds Averaged Navier Stokes (URANS) dengan pemodelan k- $\varepsilon$ pada bilangan Reynolds tinggi, untuk Cuci dan Spalding [5] menggunakan bilangan Reynolds antara $\left(0,5 \times 10^{6}<\operatorname{Re}<\right.$ $4 \times 10^{6}$ ). Singh dan Mittal [4] analisa pemodelan 2D dengan Large Eddy Simulation (LES) menggunakan bilangan Reynolds antara $\left(100<\mathrm{Re}<10^{7}\right)$. Catalano dkk. fokusnya pada bilangan Reynolds Re $0,5 \times 10^{5}$ dan $1 \times 10^{6}$ dengan koefisien drag yang kecil (koefisien drag berkurang saat Re $2 \times 10^{5}$ ) dan mereka menyimpulkan bahwa hasil Large Eddy Simulation (LES) jauh lebih akurat dibandingkan dengan Unsteady Reynolds Averaged Navier Stokes (URANS) untuk bilangan Reynolds $\operatorname{Re} \sim 1 \times 10^{6}$, tetapi mereka juga berkomentar bahwa hasil Large Eddy Simulation (LES) juga belum akurat dibandingkan dengan hasil penelitian (eksperimen).

Pemodelan k- $\varepsilon$ untuk bilangan Reynolds tinggi sudah tersedia di Computational Fluid Dynamics (CFD) kita tinggal mengatur sesuai masalah yang akan kita teliti, terutama untuk menganalisa aliran di sekitar didinding, untuk analisa komputasi numerik yang lebih efisien lagi menggunakan Large Eddy Simulation (LES) dan Direct Numerical Simulation (DNS), namun cara ini kurang akurat untuk aliran fluida subkritis. Franke dkk. [6] dan Tutar , Holdø [7] mengevaluasi hasil analisa dari Cantwell dan Coles untuk bilangan Reynolds 1,4x106. Franke dkk. [6] melanjutkan analisa dari Launder and Spalding [5] menggunakan persamaan Unsteady 
Reynolds Averaged Navier Stokes (URANS) dengan pemodelan k- $\varepsilon$ bilangan Reynolds tinggi, Tutar and Holdø [7] menggunakan pemodelan k- $\varepsilon$ bilangan Reynolds tinggi linear dan non linear, hasil analisanya untuk aliran subkritis pada koefisien drag yang kecil. Mereka juga menyimpulkan bahwa pemodelan k- $\varepsilon$ lebih akurat untuk analisa aliran turbulen pada kondisi anisotropik. Catalano dkk. juga membahas masalah koefisien drag rata-rata (averaged drag coefficient) pada Re $1 \times 10^{6}, 2 \times 10^{6}$ dan $4 \times 10^{6}$, sebagian besar analisa numerik itu semuanya hanya mencari hasil koefisien drag rata-rata saja dan hasilnya hamper mendekati dengan hasil penelitian (eksperimen).

Tujuan utama dari penelitian ini adalah untuk meneliti apakah jumlah pemodelan $\mathrm{k}-\varepsilon$ bilangan Reynolds tinggi pada diskritisasi first order upwind, second order upwind dan third order MUSCL akurat untuk menganalisa aliran fluida di sekitar dinding silinder licin dua dimensi (2D) pada bilangan Reynolds $1 \times 10^{6}$ menggunakan metode numeric, setelah itu hasilnya dibandingkan dengan penelitian Catalano dkk. dan Singh, Mittal [4].

\section{Model Matematik}

Menggunakan persamaan rata-rata Reynold dari massa dan momentum :

$$
\begin{aligned}
& \frac{\partial u_{i}}{\partial x_{i}}=0 \\
& \frac{\partial u_{i}}{\partial t}+u_{j} \frac{\partial u_{i}}{\partial u_{j}}=-\frac{1}{\rho}\left(\frac{\partial P}{\partial x_{i}}\right)+v\left(\frac{\partial^{2} u_{i}}{\partial x_{j}^{2}}\right)-\frac{\overline{\partial u_{\imath}^{\prime} u_{j}^{\prime}}}{\partial x_{j}}
\end{aligned}
$$

dimana $\mathrm{i}, \mathrm{j}=1$, 2. Berikut $\mathrm{x} 1$ dan $\mathrm{x} 2$ menunjukkan arah horizontal dan vertikal, masing masing; $\mathrm{u} 1$ dan $\mathrm{u} 2$ adalah komponen kecepatan rata-rata; $\overline{u_{\imath}^{\prime} u_{\jmath}^{\prime}}$ adalah komponen tegangan Reynolds dimana $u_{i}^{\prime}$ menunjukkan fluktuasi kecepatan; P adalah tekanan; dan $\rho$ adalah densitas dari fluida.

Tegangan Reynolds komponen, $\overline{u_{\imath}^{\prime} u_{\jmath}^{\prime}}$ a, dinyatakan dalam viskositas turbulen $v_{T}$ dan aliran gradient rata-rata dengan menggunakan pendekatan Boussinesq,

$$
\overline{u_{\imath}^{\prime} u_{\jmath}^{\prime}}=-v_{T}\left(\frac{\partial u_{i}}{\partial x_{j}}+\frac{\partial u_{j}}{\partial x_{i}}\right)-\frac{2}{3} k \delta_{i j}
$$

Di mana k adalah energi kinetik turbulen dan $\delta_{i j}$ adalah fungsi Kronecker.

Sekarang para peneliti sering menggunakan standar bilangan Reynolds tinggi pemodelan $\mathrm{k}-\varepsilon$ turbulensi (lihat Ref. [5,8]). Model ini telah diterapkan Majumdar dan Rodi [9] untuk vortex shedding flow dengan. Persamaan $\mathrm{k}$ dan $\varepsilon$ ditunjukkan:

$$
\begin{aligned}
& \frac{\partial k}{\partial t}+u_{j} \frac{\partial k}{\partial x_{j}}=\frac{\partial}{\partial x_{j}}\left(\frac{v_{T}}{\sigma_{k}} \frac{\partial k}{\partial x_{j}}\right)+v_{T}\left(\frac{\partial u_{i}}{\partial x_{j}}+\frac{\partial u_{j}}{\partial x_{i}}\right) \frac{\partial u_{i}}{\partial x_{j}}-\varepsilon \\
& \frac{\partial \varepsilon}{\partial t}+u_{j} \frac{\partial \varepsilon}{\partial x_{j}}=\frac{\partial}{\partial x_{j}}\left(\frac{v_{T}}{\sigma_{\varepsilon}} \frac{\partial \varepsilon}{\partial x_{j}}\right)+C_{1} \frac{\varepsilon}{k} v_{T}\left(\frac{\partial u_{i}}{\partial x_{j}}+\frac{\partial u_{j}}{\partial x_{i}}\right) \frac{\partial u_{i}}{\partial x_{j}}-C_{2} \frac{\varepsilon^{2}}{k}
\end{aligned}
$$

dimana $v_{T}=C \mu\left(k^{2} / \varepsilon\right)$ untuk koefisien standart diambil dari

$$
\left(C_{1}=1,44 ; C_{2}=1,92 ; C_{\mu}=0,09 ; \sigma_{k}=1,00 ; \sigma_{\varepsilon}=1,3\right)
$$

\section{Model Numerik}

Persamaan rata-rata Reynolds dari penurunan massa dan momentum, yang ada hubungannya pemodelan $\mathrm{k}-\varepsilon$ dan diskritisasi first order upwind, second order upwind dan third orde MUSCL. 
a. Aliran seragam dengan inlet $u_{1}=U_{\infty} ; u_{2}=0$. Untuk energi kinetic $k=$ $\left((3 / 2)\left(I_{u} U_{\infty}\right)^{2}\right)$ dan disipasi turbulen $\varepsilon=\left(\left(C_{\mu} k^{3 / 2}\right) /(0.1 L)\right)$ : hal ini telah disampaikan oleh Tutar dan Hold $\varnothing$ [23], hal ini telah dicoba pada intensitas turbulen $\left(I_{u}=\frac{u_{1}^{\prime}}{u_{\infty}}\right)$ adalah $0,4 \%$ dan panjang skala turbulen (L/D) adalah 0,001 .

b. Permukaan silinder no-slip condition $u_{1},=u_{2}=0$

c. $k$ dan $\varepsilon$ dekat diding silinder

$$
\begin{aligned}
& k=\frac{u_{*}^{2}}{\sqrt{C_{\mu}}}, \quad \varepsilon=C_{\mu}^{3 / 4} \frac{k^{3 / 2}}{k h_{p}} \\
& \text { untuk } \mathrm{k}=0,41
\end{aligned}
$$

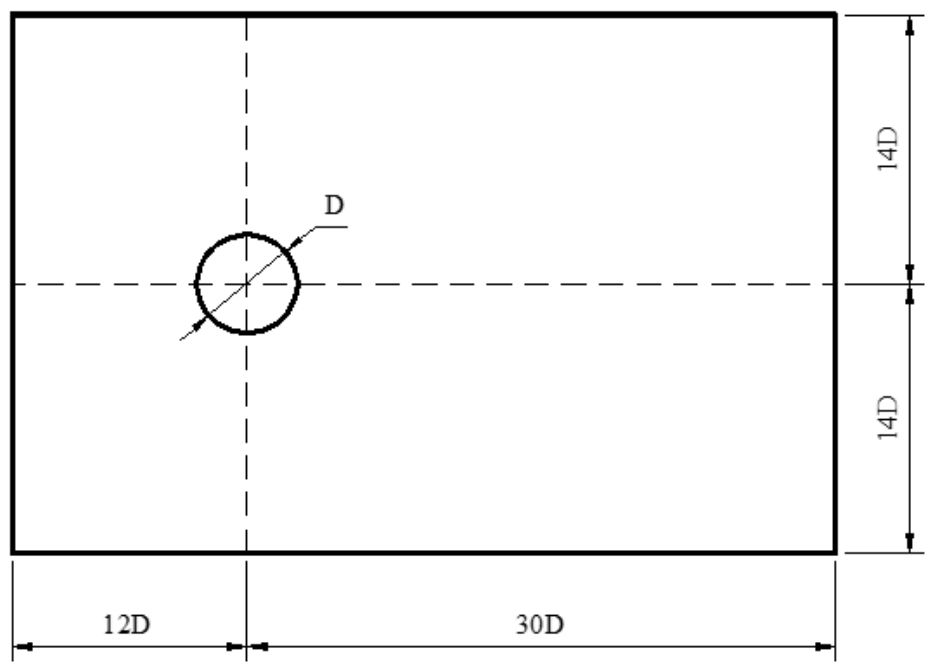

Gambar 1. Ukuran silinder dan boundary condition

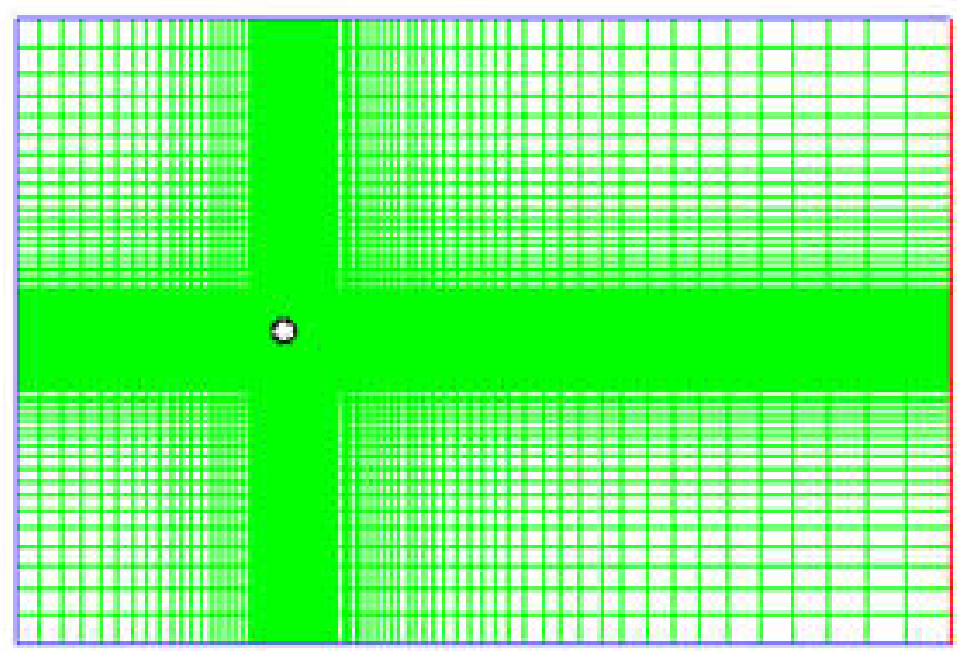

Gambar 2. Bentuk total meshing 


\section{METODE PENELITIAN}

Penelitian ini merupakan penelitian simulasi numerik menggunakan software ANXIS (Fluid Flow) [10] untuk melihat aliran udara di sekitar dinding silider sirkular. Simulasi dilakukan pada 3 model yaitu (a) first order upwind, (b)second order upwind dan (c)third order MUSCL.

\section{HASIL DAN PEMBAHASAN}

Dalam pembahasan ini menganalisa Aliran fluida pada dinding silinder sirkular dua dimensi menggunakan bilangan Reynolds yang tinggi $\left(\mathrm{Re}=10^{6}\right)$, pada pemodelan $k-\varepsilon$ dengan diskritisasi first order upwind, second order upwind dan third order MUSCL maka hasilnya ditampilkan dalam bentuk grafik:

a. Diskritisasi pemodelan $\mathrm{k}-\varepsilon$

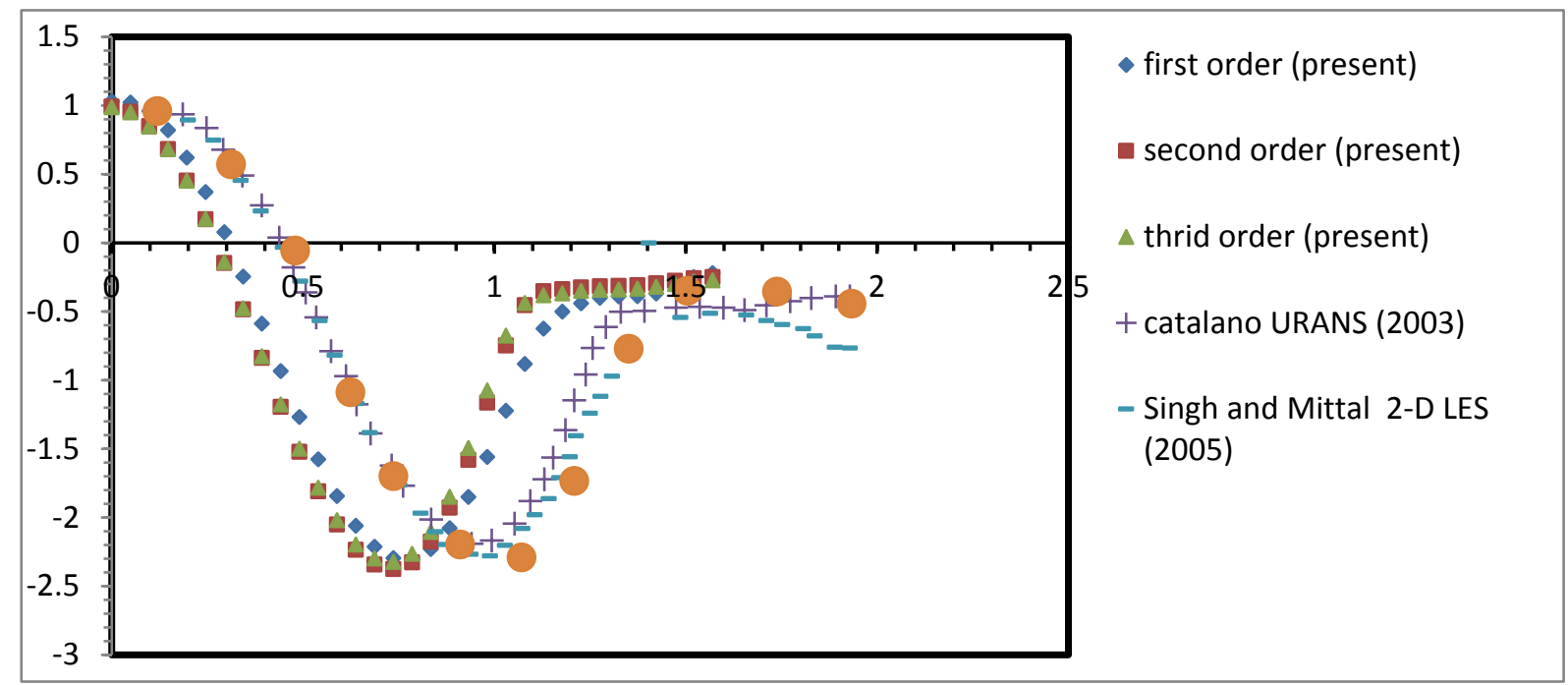

Gambar 3. Grafik Pressure Coefficient $\mathrm{Re}=1 \times 10^{6}$

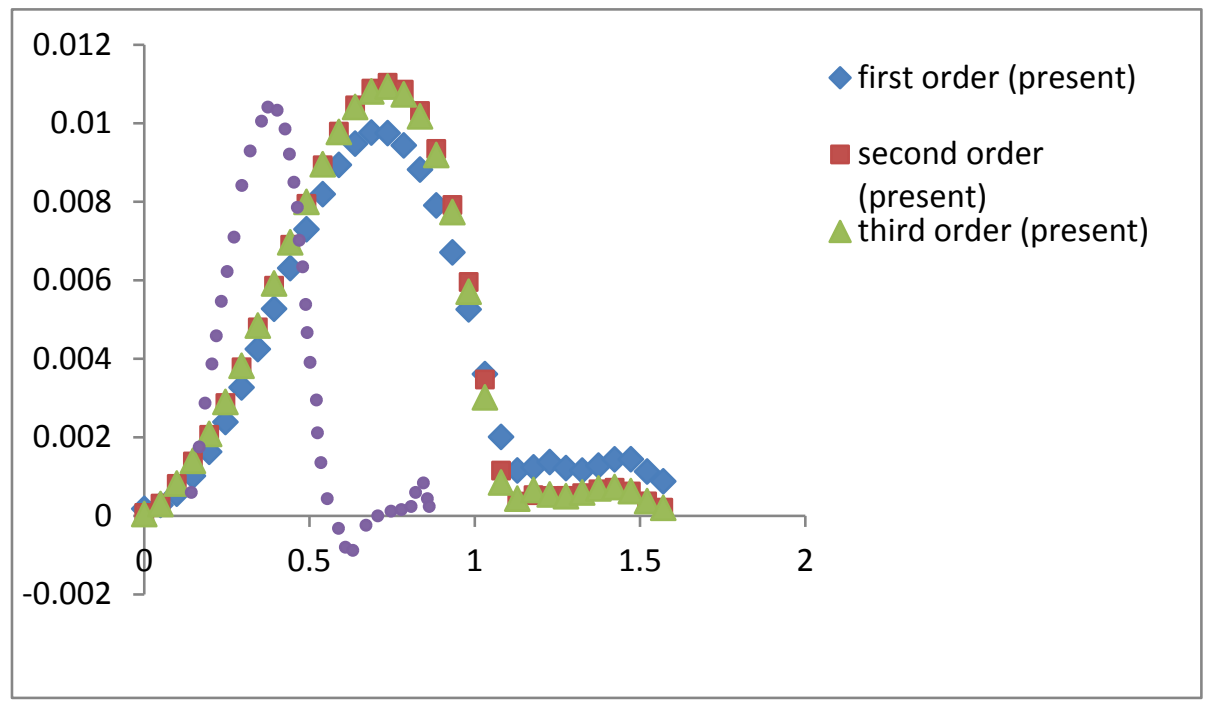

Gambar 4. Grafik Skin frictiont $\mathrm{Re}=1 \times 10^{6}$ 


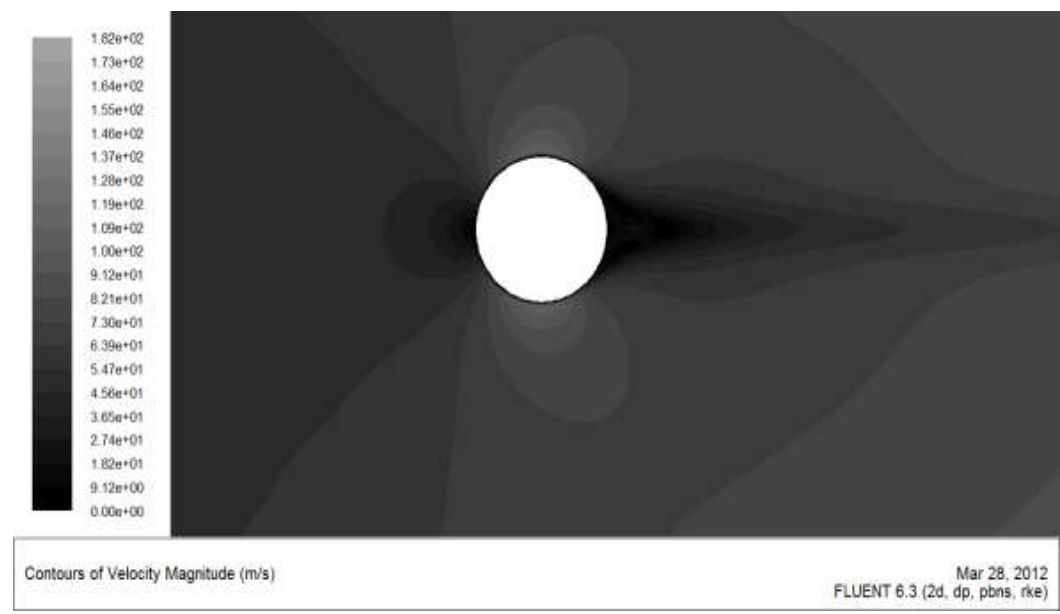

(a)

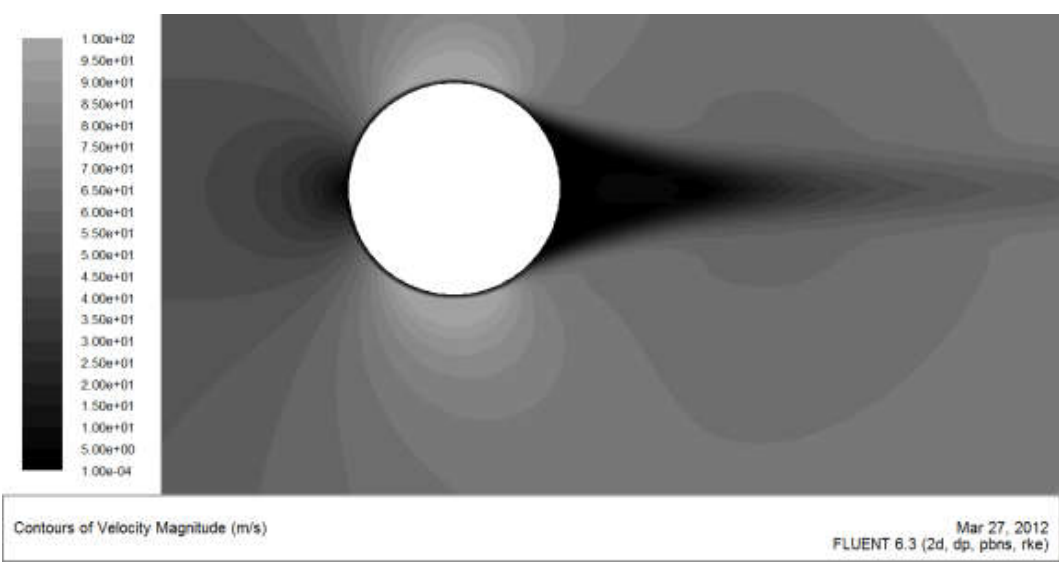

(b)

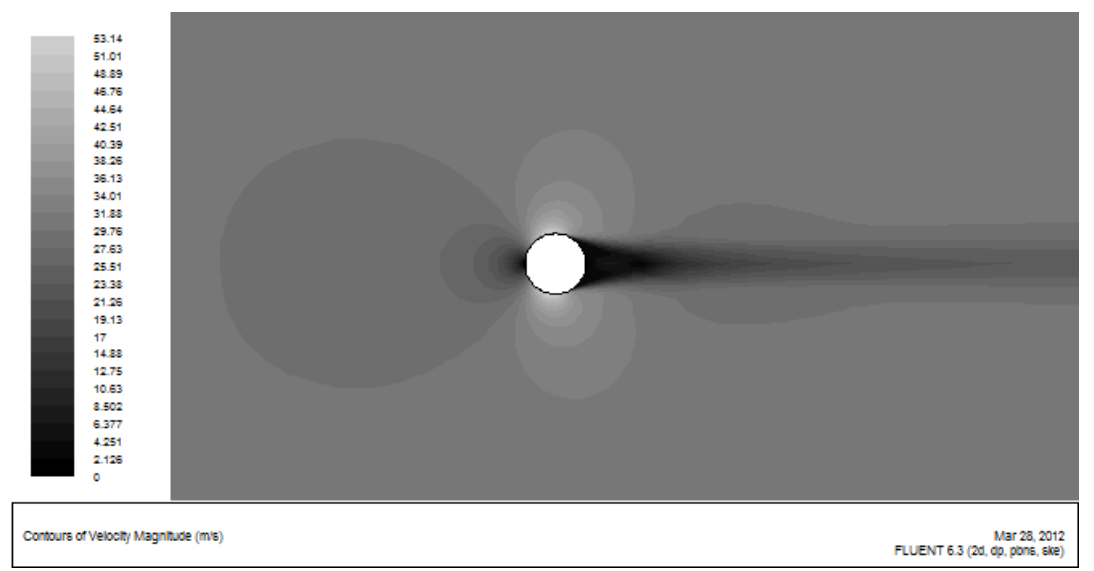

(c)

Gambar 5. Display Pressure Coefficient (a) first order upwind, (b)second order upwind dan (c)third order MUSCL 


\section{SIMPULAN DAN SARAN}

\section{Simpulan}

Analisa aliran di sekitar dinding silinder sirkuar 2D dengan metode numerik telah dilakukan pada k- $\varepsilon$ Hight Reynolds Number pada diskritisasi first order upwind, second order upwind dan third order MUSCL pada persamaan Unsteady Reynolds Averaged Navier Stokes (URANS), Model ini belum memberikan prediksi analisa yang akurat untuk aliran turbulens anisotropik, penelitian ini menunjukkan untuk menganalisa aliran fluida yang akurat maka cenderung menggunakan $\mathrm{Re}>10^{6}$, pada analisa ini juga menunjukkan dan membandingkan Pressure Coefficient dan Skin friction dengan hasil penelitian pihak lain yang terpublikasi.

Dari tiga skema aliran udara yang di teliti, simulasi aliran udara d sekitar silinder sirkular pada masing-masing skema terlihat sama tetapi memiliki hasil kontur udara yang berbeda. Hal ini terjadi karena besarnya parameter simulasi. Pada analisa ini juga menunjukkan dan membandingkan Pressure Coefficient dan Skin friction dengan hasil penelitian pihak lain yang terpublikasi.

\section{Saran}

Penelitian aliran udara pada sekitar silinder sirkular berikutnya dilakukan delam model 3D agar aliran udara di sekiar dinding silinder lebih terlihat perbedaan dari masing-masing skema.

\section{DAFTAR RUJUKAN}

[1] Sumer BM, Fredsøe J. Hydrodynamics around cylindrical structures: advanced series on ocean engineering - vol. 12. Singapore: World Scientific; 1997.

[2] Schulz KW, Meling TS. Multi-strip numerical analysis for flexible riser response. In: Proceedings of the 23rd international conference on offshore mechanics and arctic engineering; 2004. OMAE2004-51186, Vancouver, Canada.

[3] Chaplin JR, Bearman PW, Cheng Y, Fontaine E, Graham JMR, Herfjord K, et al. Blind predictions of laboratory measurements of vortex-induced vibrations of a tension riser. J Fluids Structures 2005;21:25-40.

[4] Singh SP, Mittal S. Flow past a cylinder: shear layer instability and drag crisis. Int J Numer Meth Fluids 2005;47:75-98.

[5] Launder BE, Spalding DB. Mathematical models of turbulence. London: Academic Press; 1972.

[6] Franke R, Rodi W, Scho"nung B. Analysis of experimental vortex shedding data with respect to turbulence modeling. In: Proceedings of the 7th turbulent shear flow symposium; 1989. p. 24.4.1-24.4.5. Stanford, USA.

[7] Tutar M, Holdø AE. Computational modeling of flow around a circular cylinder in subcritical flow regime with various turbulence models. Int J Numer Meth Fluids 2001;35:763-84

[8] Rodi W. Turbulence models and their application in hydraulics. A state-of-the-art review. IAHR Monograph Series. 3rd ed. Rotterdam, Netherlands: A.A. Balkema; 1993.

[9] Majumdar S, Rodi W. Numerical calculation of turbulent flow past circular cylinder. In: Proceedings of the 7th turbulentshear flow symposium; 1985. p. 3.13-25. Stanford, USA.

[10] M. Y. Setiawan, Martias, and E. Alwi, "Numerical Study of Diffuser Effect on Bluff Body: Aerodynamic Characteristics,” VANOS, vol. 2, no. 2, pp. 127-134, 2017. 


\section{Biodata Penulis}

M.Yasep Setiawan, lahir di Salimpauang, 30 September 1989. Sarjana Pendidikan di Jurusan Teknik Otomotif FT - UNP 2011. Tahun 2014 memperoleh gelar Magister Teknik di program studi Rekayasa Konversi Energi jurusan Teknik Mesin Program Pascasarjana ITS Surabaya. Staf pengajar di Jurusan Teknik Otomotif FT - UNP sejak tahun 2015 sampai sekarang.

Wawan Purwanto, merupakansalah satu staf pengajar di Jurusan Teknik Otomotif Fakultas Teknik Universitas Negeri Padang. Menyelesaikan S1 dari program studi pendidikan Teknik Otomotif Fakultas Universitas Negeri Padang, kemudian mengambil S2 di Universitas Pancasila dan mendapatkan gelar doktoral dari National Kaohsiung First University of Science and Technology Taiwan. Memiliki ketertarikan riset di bidang Teknik Otomotif dan Motor Listrik

Wanda Afnison, dilahirkan di Sariak Laweh, 9 April 1989. Menyelesaikan S1 pada program studi Pendidikan Teknik Otomotif Jurusan Teknik Otomotif FT - UNP Padang tahun 2011 dan pendidikan Pascasarjana (S2) Magister Teknik di jurusan Teknik Mesin Program Pascasarjana ITS Surabaya dengan bidang konsentrasi Desain Sistem Mekanikal pada tahun 2015. Sejak tahun 2015 sampai sekarang menjadi staf pengajar di jurusan Teknik Otomotif FT - UNP.

Nuzul Hidayat, lahir di Tigo Suku, 16 Januari 1987. Merupakan staf pengajar dijurusan Teknik OtomotifFT UNP mulai daritahun 2013 hingga Sekarang. Penulis menamatkanpendidikan level sarjana di prodi PendidikanTeknik Otomotif FT UNP dan Jenjang MagisterTeknik di prodi Teknik Mesin Bidang Keahlian Rekayasa Konversi Energi di Institut Teknologi Sepuluh Nopember. Beberapa temaunggulan dalam penelitian penulis antara lainmekanika fluida, motor diesel dll. 